Original Research Paper

\title{
Forecasting the Diffuse Solar Radiation by using a New Modeling over Saudi Arabia
}

\author{
Samy A. Khalil \\ Department of Solar, National Research Institute of Astronomy and Geophysics, Egypt
}

\author{
Article history \\ Received: 25-02-2021 \\ Revised: 13-04-2021 \\ Accepted: 15-04-2021 \\ Email: samynki@yahoo.com
}

\begin{abstract}
Within the arranging and execution assessment of solar energy projects, particularly within the planning and estimation of solar photovoltaic sources as elective energy sources within the future, exact evaluation of Diffuse Solar Radiation (DSR) is one of the essential and basic issues. The target of this article is to use the new model to predict DSR in four different locations in Saudi Arabia. The author explored the available meteorological and radiation data. The data covers the 25 years from 1990 to 2014 and were measured at Al-Baha, Abha, Jeddah and Taif locations in Saudi Arabia. Through detailed statistical evaluation and analysis, 19 empirical models were tested to construct the best empirical model to estimate the monthly average daily DSR of Saudi Arabia. Using widely used statistical errors, namely MBE, MPE, RMSE, U95, R, t-test and GPI the proposed correlation model was compared with 19 models provided in the literature. Through this analysis, the cubic empirical equation model is selected as the good model. Compared with these existing models, this model reveals accurate results with minimal statistical errors. Based on these results, Model 22 gives the highest GPI value. The conclusion is the cubic equation model of the diffusion fraction (i.e., $D / G=0.215+2.123\left(\mathrm{~S} / \mathrm{S}_{\mathrm{o}}\right)-3.547\left(\mathrm{~S} / \mathrm{S}_{\mathrm{o}}\right)^{2}+5.142$ $\left(\mathrm{S} / \mathrm{S}_{\mathrm{o}}\right)^{3}$ is the best agreement model that has been mentioned in the previous discussion. This model is a generalized equation in Saudi Arabia, which can forecast the monthly average daily diffuse radiation on the horizontal plane at any site under similar climatic conditions without the measured climatic conditions. Experts or architects can use this model to perform site selection and technical and financial evaluation of solar energy applications and photovoltaic technology.
\end{abstract}

Keyword: Diffuse Solar Radiation (DSR), Statistical Indicators, Solar Energy, Meteorological Data and Empirical Model

\section{Introduction}

Solar radiation data is the basic input for solar applications, such as photovoltaic, solar thermal systems and passive solar design. The data should be reliable and can be used at any time to design, optimize and evaluate the performance of solar technology at any site. However, it is not economically feasible to install solar radiation measuring instruments wherever possible. Therefore, the use of mathematical models to forecast the solar radiation in a given area has proved to be a viable option based on the measurement results of limited locations ( $\mathrm{Li}$ et al., 2015; Shukla et al., 2015a). Unfortunately, in many developing countries, solar radiation measurement is not yet available because they cannot afford the equipment and measurement technology. Hence, it is vital to create methods for evaluating solar radiation based on more promptly accessible meteorological data. Within the design and execution examination of solar energy projects, particularly within the design and measure assurance of solar PV as a future alternative energy source, exact forecast of Diffuse Solar Radiation (DSR) is essential. Careful thought of DSR can way better assess the productivity of the solar system (Shukla et al., 2015b; 2016a; Jamil et al., 2016).

In addition, in several regions of the world, there is no or very little measurement of diffuse solar radiation. Because of their wide application in other places, they can measure total horizontal irradiance and other standard meteorological variables, such as sunshine duration, 
temperature and relative humidity. In the field of meteorology and agriculture, given global solar radiation data and some meteorological parameters, the diffusion component can be obtained through various correlations. Recently, extensive research has been conducted in many parts of the world to estimate DSR using the most widely available data. Many authors have proposed empirical formulas to use the clearness index (Kt: The ratio of global solar radiation to extraterrestrial solar radiation) (Shukla et al., 2016b; 2015c; 2016c), or use the fraction of hours of sunshine (Shukla et al., 2016d, e) to forecast the monthly average on a horizontal surface of DSR, or in combination (Shukla et al., 2016f; Duffie and Beckman, 2006; Karatasou et al., 2003). A model for predicting daily DSR using sunshine fraction (the ratio of sunshine duration to the maximum possible sunshine time), clarity index and haze factor is also proposed (Al-Mohamad, 2004). Facts have proved that the model that uses both the clarity index and the sunshine score is the best choice for estimating DSR.

The utilization of solar energy will facilitate scale back the demand for standard energy. Therefore, owing to this, solar power is taken into account to be the proper resolution to the energy crisis facing the globe nowadays (Diez-Mediavilla et al., 2005; Tarhan and Sar1, 2005; Aras et al., 2006). During this method, radiation information should be established for places of interest that is sometimes a requirement for the institution and commission of star facilities. In any case, it's not possible to form careful observations of native environmental condition. This can be the case for several developing countries (such as Saudi Arabia). Though these countries could have high radiation potential, they lack comfortable radiation info results in fewer energy plans to be explored and enforced (Noorian et al., 2008; De Miguel et al., 2001).

The quality of radiation is typically outlined in step with its composition, specifically incident and diffuse solar radiation. Among these elements, the number of diffuse radiation is usually unsure, as a result of additionally to location parameters; it's chiefly littered with several native geographic factors and climatically characteristics. Most accessible information bases are equipped with data on world radiation and need info on diffuse radiation. This can be because of the sometimes higher value of putting in a meteorological workplace to examine elements. Therefore, empirical models are sometimes wont to measure diffuse radiation. The written kind proposes a range of various models to estimate the common monthly average radiation, that uses input factors (such as world radiation and daytime) and different climatically factors (such as humidness, pressure, precipitation and temperature) to estimate. Among these, world radiation and sunshine amount are imperative factors used at intervals the advancement of experimental models for diffuse radiation
(Khorasanizadeh and Mohammadi, 2016; Aras et al., 2006; Boland et al., 2001).

The base target of this study is to find the foremost correct empirical from the literature for forecasting monthly average daily of DSR on a surface for Al-Baha, Abha, port and metropolis locations across the Saudi Arabia. Several empirical models are collected from the literature. For this purpose, twenty-five years from 1990 to 2014 of domestically measured information were obtained a \{part of the Meteorological and Environmental Protection Agency (MEPA) in Saudi Arabia and another part of the station in Al-Baha University. This information is divided into 2 information sets such every dataset contains twenty-five years of pyranometer data measurements. The first dataset is employed for determinative the coefficients of 19 empirical radiation models, whereas the second dataset is employed for testing the accuracy of those models exploitation varied indicators within the same chosen locations throughout the amount time from 2015 to 2018 . The most effective acting model is additionally compared against nineteen models found at intervals the literature that were developed exploitation measured information from climates kind of like the climate of the Saudi Arabia.

\section{Literature Overview of Present Research}

The models accessible among the literature were developed victimization several purposeful forms, sort of predictors and for varied time resolutions. The first kind to induce the diffuse radiation was a second degree polynomial as operate of clearness index (Boland et al., 2008). Their correlation is taken under consideration one among the pioneering works among the among the radiation analysis. Their reasonably correlation has been used by many researchers over the years by calibrating the coefficients. This can be discovered in a very sort of comparable approaches in varied analysis works projected for diversified locations (Yao et al., 2017; Oliveira et al., 2002; Tarhan and Sar1, 2005; Jacovides et al., 2006; Liu and Jordan, 1960). Such classical practices square measure extended by El-Sebaii et al. (2010); Bashahu (2003); El Mghouchi et al. (2016); Jin et al. (2004), where fraction was correlative with sunshine quantity, whereas others researchers correlative correlation fraction with the sky-clearness index like (Ulgen and Hepbasli, 2003; Dervishi and Mahdavi, 2012; Khahro et al., 2015). Different meteorological factors have collectively been deployed to determine to determine radiation models (Li et al., 2012a; Cao et al., 2017).

In later associate degree extended time, varied analysts have investigated the probability of assorted relationships for estimation of diffuse radiation. Assessed four existing empiric relationships to calculate the worldwide, diffuse and bar radiation for Tetuan city, Morocco and pictured the appropriateness of show supported the factual examination 
(Jamil and Akhtar, 2015). Inferred a diffuse radiation show with useful frame comparative to Liu and Jordan show utilizing the measured knowledge of seventy-eight locations in China, MBE and RMSE were wont to factually analyze the appliance of models to a lower place the areas thought-about, a pair of trendy models connecting diffuse fraction with sky-clearness list (first and third-order polynomial) were created and compared with sixteen accessible models from writing (El-Sebaii and Trabea, 2003; Tapakis et al., 2016).

The created models were found to possess superior execution for the venue thought-about. Compared eight diffuse radiation models utilizing measured knowledge of worldwide radiation for Austrian capital, Austria, they expressed that standardization of the models can somewhat move forward the execution of the models (Wattan and Janjai, 2016). Derived the horizontal diffuse radiation victimization the accessible models from literature, they developed nine new diffuse radiation models correlating diffuse fraction and diffusion coefficient with relative sunshine quantity and sky-clearness index (Ulgen and Hepbasli, 2009). Investigated worldwide, beam and diffuse sun powered radiation estimation for Aligarh, Asian nation and projected show for diffuse division in terms of sky-clearness record with an unused set of regression coefficients (Kaygusuz, 1999; Bakirci, 2012). Models were projected by Paulescu and Blaga (2016) connecting diffuse constant and diffuse division with skyclearness index and relative sunshine quantity. Examined execution of fourteen radiation models at a pair of locales within the tropics for foreseeing hourly diffuse sky irradiation on inclined surfaces unit of measurement found in (Magarreiro et al., 2014). Projected eight new models beneath four different categories to survey diffuse radiation; and talked regarding their application and appropriateness in three major areas in Turkey. They too urged utilize of created models for areas beneath comparable climatic conditions (Li et al., 2011). Measured knowledge for Trabzon, Turkey and created seven experimental models to gauges diffuse radiation supported air parameters. Comparative technique was taken once by Li et al. (2012b); Safaripour and Mehrabian (2011), administrative body projected vi new models supported the cruel values of sun-based radiation obtained out of 10 models accessible within the writing to assess the monthly average daily radiation for Erzurum, Turkey. Compared the appliance the appliance radiation models on Azorean region for the assessment of the potential of other energy technologies in (Marques Filho et al., 2016; Despotovic et al., 2016). Counseled pair of correlations for estimation of diffuse radiation, projected models were compared with eight existing models from literature (Khorasanizadeh et al., 2014). Assessed and compared existing diffuse radiation models for 267 different sites all over the world; classified and stratified the models for quality of estimation (Ekren, 2013 Bakirci, 2015; Boland et al., 2013). Analyzed the radiation knowledge of assorted destinations for a few of states within the world, encourage, they performed categorization of empiric models utilized in estimation of diffuse radiation and examined their applications (Khalil and Shaffie, 2013). Created and evaluated models for estimation of diffuse radiation supported climatically components for Turkey (Khalil, 2007; Bortolini et al., 2013). Displayed models for diffuse radiation and jointly examined assessed hourly direct ancient radiation (Bailek et al., 2018). Experimental relationships for diffuse radiation from worldwide radiation and sunshine length, performed comparative examination of radiation for Cairo, Egypt utilizing whole totally different models for level and slanted surfaces (Boukelia et al., 2014). Created 10 experimental models connecting the diffuse division and so the relative sunshine quantity knowledge at areas for country, they what is more created generalized relationships for estimation of diffuse star irradiance in different locales of country (Abal et al., 2017). ten models for hourly diffuse light-weight and assessed their execution, every in their distinctive and regionally balanced forms, against knowledge recorded at 5 locales from a subtropical temperate zone within the southern a section of South America, they elaborate that the multi-variable models outflank the sole variable models in terms of scattering (Jafari and Javaran, 2012). Created twelve relationships between diffuse radiation with single input variable within the shape of sky-clearness index and relative sunshine length for Kerman, Iran, supported measurable take a glance at it fully was inferred that the foremost superb show encompasses an instantaneous type connecting diffusion coefficient with sky-clearness index (Khatib et al., 2011). Experimental models supported a combination of sky-clearness index and relative sunshine quantity, have rarely been investigated in writing, as a result of it were a touch style of case ponders square measure elaborate, propose such a gathering of sky-clearness index and sunshine quantity wont to wont to radiation models for country (Al-Hamdani et al., 1989). Created demonstrate connecting sky-clearness index, relative sunshine quantity, or a combination of every, it fully was finished that the gathering of sky-clearness index and sunshine quantity provides higher precise comes regarding within the estimation of diffuse radiation, relationships were created within the frame of diffuse fraction and diffusion constant as a chunk of relative sunshine quantity and skyclearness index and a combination of them (Khorasanizadeh and Mohammadi, 2016). Created diffuse division models supported sky-clearness and sunshine length and a combination of them beneath three categories for Tabass, Iran, interrogation polynomial show with a pair of input factors was urged to perform the leading among the created models (Jiang, 2009a; Mubiru and Banda, 2007; Khorasanizadeh et al., 2014). Established simple technique victimization neural network-based 
technique for diffuse radiation, diffuse radiation was sculptural victimization international radiation and different earth science parameters by utilizing neuralnetwork technique (Lou et al., 2016; Soares et al., 2004). Performed estimation of worldwide energy for 5 sites in Asian nation victimization linear, nonlinear, ANN and logic models for shrewd and finished that ANN-based model best estimates the diffuse radiation (Khorasanizadeh et al., 2016; Jiang, 2009b).

They finished that prime accuracy are going to be achieved by the mixtures of two or three most relevant inputs. It's apparent from literature that empirical models supported international radiation and sunshine quantity unit of measurement among the foremost common forms exploited. It's discovered kind the literature that although several studies square measure targeted on the event and analysis of diffuse radiation models. Further, the comparison of models for estimation of diffuse radiation among the shape diffuse fraction and diffusion constant of single variable and a couple of variable input for wet subtropical climate has not been mentioned in literature. It's of express interest to believe the models for estimation of diffuse radiation as single variable input and two-variable input and compare the performance of such models.

\section{Geography and Climate of Selected Locations in Saudi Arabia}

Saudi Arabia may be a nation arranged in Southwest Asia and incorporates roughly four-fifths of the Middle Eastern Peninsula between scopes $16^{\circ}$ and $33^{\circ} \mathrm{N}$ and between longitudes $34^{0}$ and $56^{\circ} \mathrm{E}$. Saudi Arabia contains the world's biggest persistent sand desert, Al-Rub Al-Khali (the Purge Quarter). The desert spring locale of Al-Ahsa involves much of the Eastern Area as appeared in Fig. 1. KSA is well put for capitalizing solar energy with the average daily solar radiation level coming to $6 \mathrm{kWh} / \mathrm{m}^{2}$ and $80-90 \%$ of clear sky days over the year. The annual solar radiation level comes to over $2400 \mathrm{kWh} / \mathrm{m}^{2}$ as appeared in Fig. 2 (Božnar et al., 2017). KSA climate is for the most part hot and dry, in spite of the fact that evenings are cool and ices happen in winter. The humidity along the coasts is high. The temperature amid the summer is tall, coming to well over $45^{\circ} \mathrm{C}$, with by and large cold evenings. Extraordinary temperatures well underneath ${ }^{\circ} \mathrm{C}$ are frequent in winter. The average monthly temperatures watched in KSA over the final century extended between a low of $15.5^{\circ} \mathrm{C}$ from December to February to $30^{\circ} \mathrm{C}$ from May to September (Božnar et al., 2017).

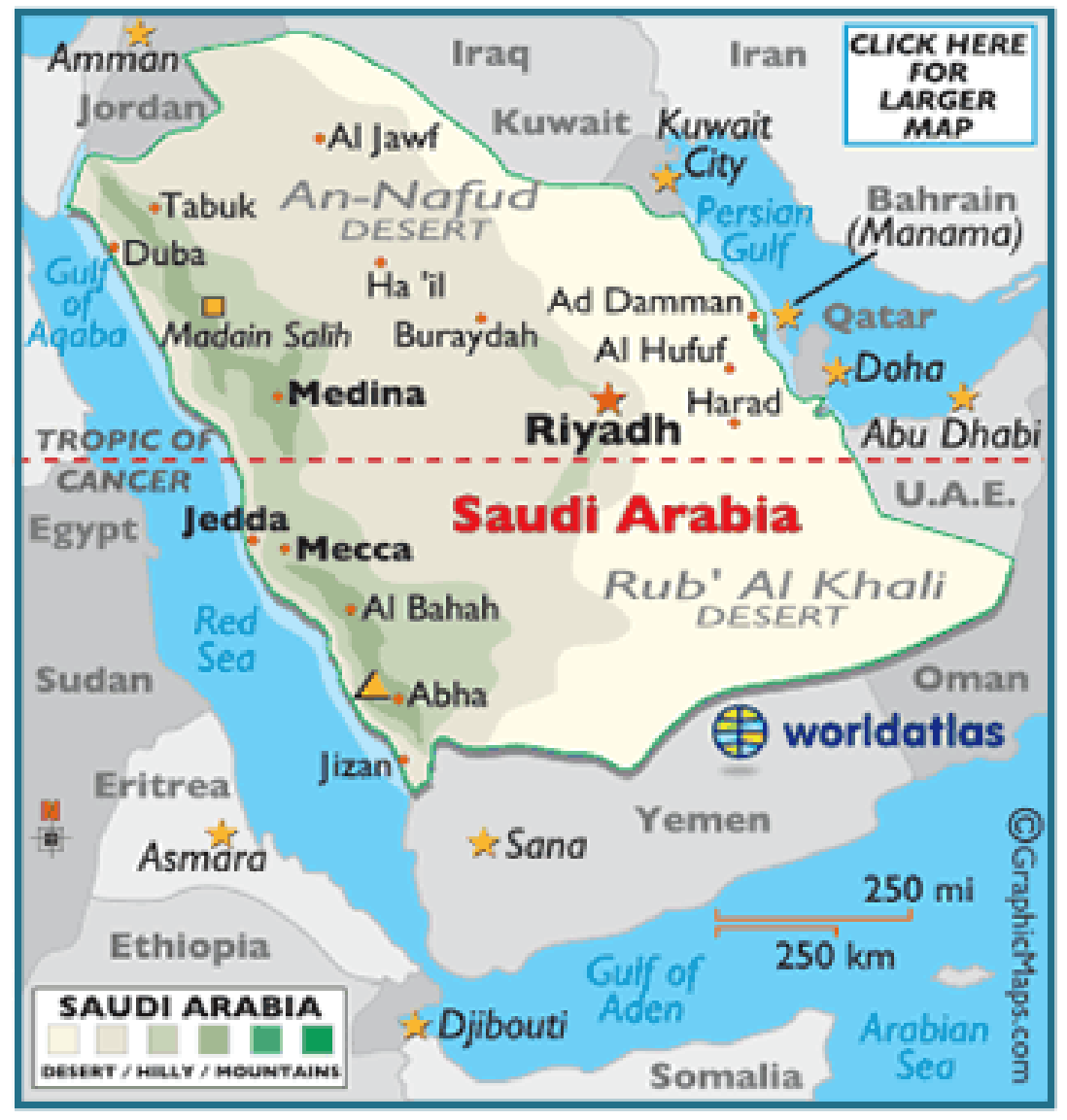

Fig. 1: Geographic map of Saudi Arabia 


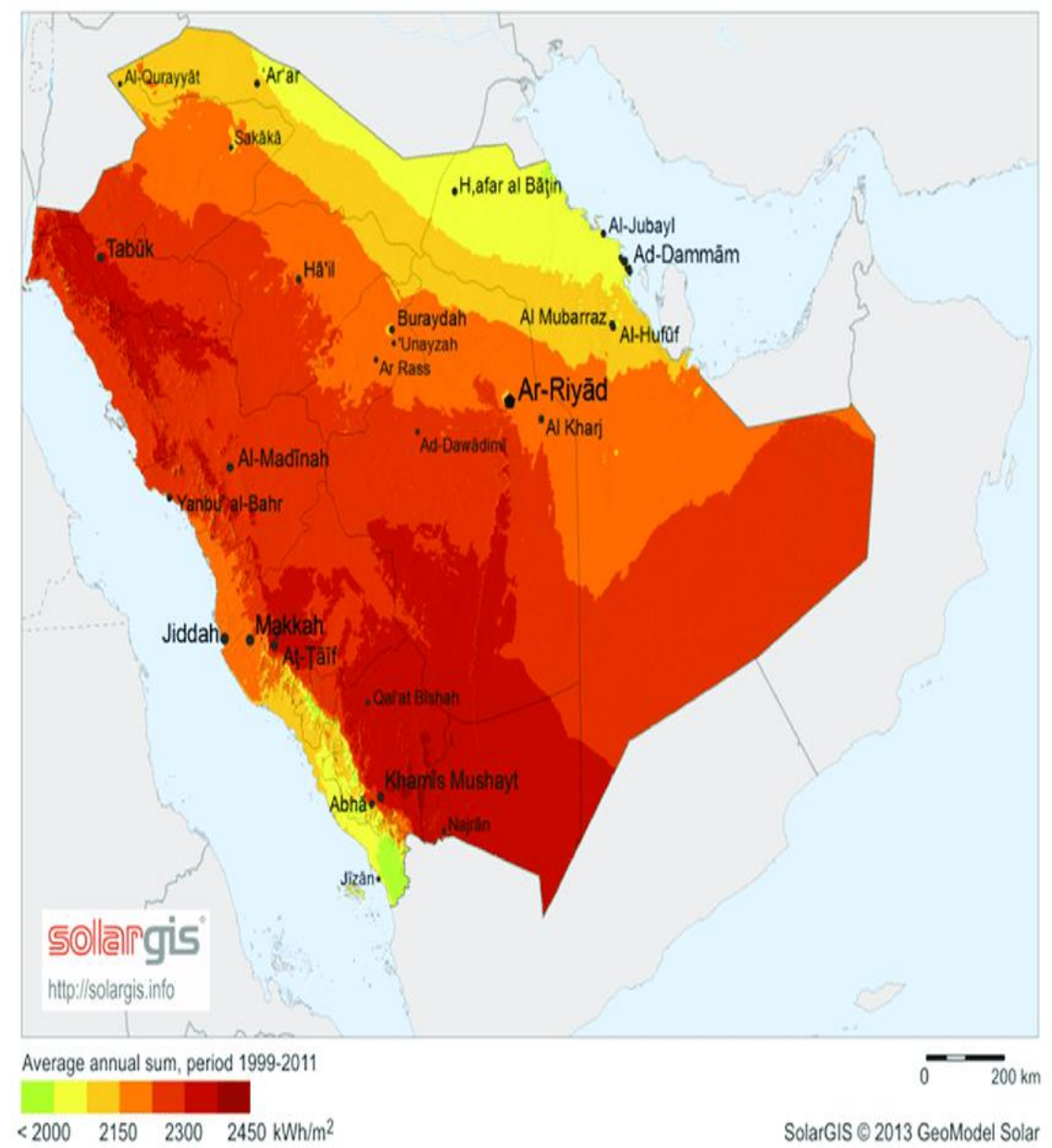

Fig. 2: Solar radiation map of Saudi Arabia

Table 1: Information of the selected locations in the present study

\begin{tabular}{lcclr}
\hline Locations & Al-Baha & Abha & Jeddah & Taif \\
\hline Latitude $\left({ }^{\circ} \mathrm{N}\right)$ & 20.02 & 18.13 & 21.32 & 21.16 \\
Longitude $\left({ }^{\circ} \mathrm{E}\right)$ & 41.20 & 42.30 & 39.11 & 40.24 \\
Elevation $(\mathrm{m})$ & 2470 & 2200 & 12 & 1879 \\
The period of data & $1990-2014$ & $1990-2014$ & $1990-2014$ & $1990-2014$ \\
Mean T $\left({ }^{\circ} \mathrm{C}\right)$ & 23.4 & 24.7 & 29.2 & 25.4 \\
\hline
\end{tabular}

The topographical areas in Saudi Arabia are exceedingly favorable for solar energy speculation due to its nearness to the European Union and as a portion of one of the Sunbelt countries (Şenkal and Kuleli, 2009). The geological dispersion of the chosen areas within the present research is illustrated within the map displayed in Fig. 1 and the solar radiation map of Saudi Arabia displayed in Fig. 2. The assist data almost the chosen area subtle elements is given in Table 1 .

Al-Baha city is separated topographically into three verifiable parts: Sarah, which contains the tall Hejaz mountains portrayed by calm environment and wealthy plant spread due to commonly tall annually precipitation,
Tihama which is the swamp, ocean shore a front region westbound of the Hejaz depicted by irritating and the damp air and essentially no precipitation standard and the eastern inclines delineated by a rise of 1,550 to $1,900 \mathrm{~m}$ over ocean level with cool winters, bubbling summers and little plant spread. The most noteworthy city within the space, both in individuals and the zone is Baljurashi the coming about one is Al-Mandaq. In Tehama, there are two basic metropolitan systems: Qilwah and Al-Mikhwah (Şenkal and Kuleli, 2009).

Abha is organized within the southern zone of Asir at a rising of around 2,270 $\mathrm{m}$ over ocean level. Abha lies on the western edge of Mount Al-Hijaz close Jabal Sawda, 
the foremost raised best Saudi Arabia. With regard to Asir Mountains as a noteworthy portion of the Sarawat, the scene is notwithstanding coordinated by the Sarawat Mountains. The environment of Abha is semi-dry and it is impacted by city's tall stature. The city's air is customarily smooth, dependably, getting recognizably cooler amid the "low-sun" season (Khalil et al., 2019).

Jeddah was a critical city of Hejaz Vilayet, the Kingdom of Hejaz and other commonplace political substances as appeared by Hijazi history books. Jeddah joins a dry environment beneath Koppen's climate diversion arranges, with a tropical temperature run. Jeddah holds its warm temperature in winter. Summer temperatures are unfathomably irritating. Summers are besides amazingly sweltering, with dew concentrates. Precipitation in Jeddah is by and large deficiently and routinely happens in November and December (Khalil et al., 2019; Şenkal and Kuleli, 2009).

Taif lies south east of Jiddah and the Heavenly City of Mecca. Taif is organized within the mountains above Makkah and Jeddah. Within the winter the temperature can discover a workable pace as three degrees and as tall as eighteen degrees. In spring and harvest time, it a few of the time deluges and the environment are tender with a small infection wind. Taif's rise gives it a distant cooler and lovelier air than either Jeddah or Makkah and without the ungainly clamminess of the past (Božnar et al., 2017).

\section{Materials and Methods}

Numerical expression of the estimation relationship of diffuse solar radiation can be classified in to three categories as takes after; the primary, diffuse solar radiation from sunshine duration, the moment, connection between diffuse solar radiation and clearness index and the third, relationship combining clearness index and sunshine duration. Where; we utilized $(G)$, is the monthly mean daily global solar radiation, $\left(K_{t}=G / G_{o}\right)$ is the clearness index, $G_{o}$ is the extraterrestrial solar radiation (was calculated from (Klein, 1977), $(D)$ is the monthly mean daily diffuse solar radiation, $(S)$ is the monthly mean daily number of hours of observed bright sunshine and $\left(S_{o}\right)$ is the monthly mean daily number of hours of sunshine between sunrise and sunset.

The linear relationships connecting $(D / G)$ and $\left(S / S_{o}\right)$ which have the forms:

$$
\begin{aligned}
& D / G=0.791-0.635\left(S / S_{o}\right) \\
& D / G=0.79-0.59\left(S / S_{o}\right) \\
& D / G=0.697-0.577\left(S / S_{o}\right) \\
& D / G=0.754-0.651\left(S / S_{o}\right)
\end{aligned}
$$

$$
D / G=0.163+0.478\left(S / S_{o}\right)-0.655\left(S / S_{o}\right)^{2}
$$

$D / G=0.31+0.0 .078\left(S / S_{o}\right)-0.314\left(S / S_{o}\right)^{2}$

$$
D / G=-2.313+7.393\left(S / S_{o}\right)-5.314\left(S / S_{o}\right)^{2}
$$

$D / G=1.135-2.126\left(S / S_{o}\right)+1.717\left(S / S_{o}\right)^{2}-0.585\left(S / S_{o}\right)^{3}$

$D / G=-0.5928+4.604\left(S / S_{o}\right)-6.857\left(S / S_{o}\right)^{2}+3.068\left(S / S_{o}\right)^{3}(9)$

The second relationships between diffuse solar radiation and clearness index:

$$
\begin{aligned}
& D / G=1.00-1.13\left(K_{t}\right) \\
& D / G=1.017-1.159\left(K_{t}\right) \\
& D / G=0.958-0.982\left(K_{t}\right) \\
& D / G=3.49-9.03\left(K_{t}\right)+6.22\left(K_{t}\right)^{2} \\
& D / G=1.39-4.027\left(K_{t}\right)+5.531\left(K_{t}\right)^{2}-3.018\left(K_{t}\right)^{3}
\end{aligned}
$$

The third, correlation combining clearness index and sunshine duration:

$$
\begin{aligned}
& D / G=0.89-0.74\left(K_{t}\right)-0.18\left(S / S_{o}\right) \\
& D / G=0.93-0.59\left(S / S_{o}\right)-0.16\left(K_{t}\right) \\
& D / G=0.80-0.07\left(S / S_{o}\right)-0.75\left(K_{t}\right) \\
& D / G=0.879-0.575\left(K_{t}\right)-0.323\left(S / S_{o}\right) \\
& D / G=1.194-0.838\left(K_{t}\right)-0.446\left(S / S_{0}\right)
\end{aligned}
$$

Equation (3, 8, 12, 18 and 19) suggested by Gopinathan (1988) are based on data from six locations in the South African region. Equation (1, 4 and 12) we developed by (Iqbal, 1979), Eq. (4) by Lewis (1983), Eq. (18) by Page (1961) and Eq. (14) by Liu and Jorden (1960), Eq. (9) by the (Sabzpooshani and Mohammadi, 2014), the Mohammed model Eq. (15) Mohammadi et al. (2016), Ibrahim model Eq. (2) (Ibrahim, 1985), Trabea model Eq. (16) (Trabea, 1999), Elminirmodel Eq. (17) (Elminir et al., 2007), Boukelia models Eq. (6, 7 and 13) (Boukelia et al., 2014). 


\section{Computation Techniques}

A few relationships, which have a place to the distinctive categories said within the over section, are accessible for computing diffuse solar radiation values. The coefficients of these relationships are for the most part diverse for geographic and climatic districts. Among the over relationships Pag's and Liu and Jordin's models are most broadly utilized. The model proposed by Gopinathan could be a more recent one and its appropriateness needs to be tested assist in other locales.

In the present research, the results mentioned in the above section are used with the following correlations to express the dependence of diffuse radiation on various parameters and dividing models of Eq. (20-26) are case 1, models of Eq. (27-32) are case 2 and models of Eq. (33-38) are case 3:

\section{Case 1}

$$
\begin{aligned}
& D / G=a+b\left(S / S_{o}\right) \\
& D / G=a+b\left(S / S_{o}\right)+c\left(S / S_{o}\right)^{2} \\
& D / G=a+b\left(S / S_{o}\right)+c\left(S / S_{o}\right)^{2}+d\left(S / S_{o}\right)^{3} \\
& D / G=a+b \log \left(S / S_{o}\right) \\
& D / G=a+b \exp \left(S / S_{o}\right) \\
& D / G=a+\exp b\left(S / S_{o}\right) \\
& D / G=a+b \log \left(S / S_{o}\right)+c\left(S / S_{o}\right)
\end{aligned}
$$

Case 2

$$
D / G=a+b\left(K_{t}\right)
$$

$$
\begin{aligned}
& D / G=a+b\left(K_{t}\right)+c\left(K_{t}\right)^{2} \\
& D / G=a+b\left(K_{t}\right)+c\left(K_{t}\right)^{2}+d\left(K_{t}\right)^{3} \\
& D / G=a+b \log \left(K_{t}\right) \\
& D / G=a+b \exp \left(K_{t}\right) \\
& D / G=a+\exp b\left(K_{t}\right)
\end{aligned}
$$

\section{Case 3}

$$
D / G=a++b K_{t}+c\left(S / S_{o}\right)
$$

$$
\begin{aligned}
& D / G=a++b K_{t}+c\left(k_{t}\right)^{2}+d\left(S / S_{o}\right)+e\left(S / S_{o}\right)^{2} \\
& D / G=a++b K_{t}+c\left(k_{t}\right)^{2}+d\left(k_{t}\right)^{3} \\
& +e\left(S / S_{o}\right)+f\left(S / S_{o}\right)^{2}+g\left(S / S_{o}\right)^{3} \\
& D / G=a++b \log \left(K_{t}\right)+c \log \left(S / S_{o}\right) \\
& D / G=a++b \exp \left(K_{t}\right)+c \exp \left(S / S_{o}\right) \\
& D / G=a++\exp \left(b K_{t}\right)+\exp \left(c S / S_{o}\right)
\end{aligned}
$$

where, $a, b, c, d, e, f$ and $g$ are regression coefficients that depend on the site. The measured values of global solar radiation and diffuse solar radiation obtained with Epply Pyranometer, together with the corresponding sunshine duration values for the different selected locations in Saudi Arabia are used in linear, multilinear and polynomical regression analysis to obtained values of the regression coefficients of Eq. (20-38), the values of regression coefficients are listed in Table 1.

\section{Statistical Analysis}

Created models under every class were assessed with the assistance of factual instruments. Probably the most generally acknowledged and mainstream measurable instruments are utilized to assess the presentation of the created models for assessment of diffuse sun oriented radiation. Following are the measurable devices depicted beneath: Mean Bias Error (MBE), Mean Absolute Error (MAE), Root Mean Square Error (RMSE), Mean Percentage Error (MPE), Uncertainty at $95 \%\left(U_{95}\right)$ and $t$-statistics ( $t$-stats) (Ruiz-Arias et al., 2010; Furlan et al., 2012; Li et al., 2012b; Lemos et al., 2017). These are described below.

\section{Mean Bias Error (MBE)}

Mean bias error to assess the precision of the forecast data from the models depicted above, this test gives data on the long-term execution of a model. A low MBE value is wanted. A negative value gives the average amount of underestimation within the calculated value. So, one disadvantage of MBE is that overestimation of an individual observation may cancel underestimation in an isolated observation. We can be obtained the values of MBE as follow:

$M B E=\frac{1}{n} \sum_{i=1}^{n}\left(G_{\text {di.calc. }}-G_{\text {di.meas. }}\right)$

The subscript (i) refer to the $i$ th value of the daily solar irradiation, $(n)$ is the number of the daily diffuse solar 
irradiation data. The subscripts "calc." and "meas." refer to the calculated and measured daily diffuse solar irradiation values, separately (Kambezidis et al., 2017; Bouzid and Ghellai, 2015).

\section{Root Mean Square Error (RMSE)}

RMSE is used to converse with the execution of show by setting up a correlation among estimated and anticipated qualities. The model with more minute worth is considered to have best execution when contrasted with exhibit having more prominent estimation of RMSE. RMSE persistently have a positive worth and in a perfect world is zero for glorify gauges. Numerically RMSE is depicted as (Li et al., 2011; El-Sebaii et al., 2010):

$$
R M S E=\left[\frac{1}{n} \sum_{i=1}^{n}\left\{\left(G_{\text {di.calc. }}-G_{\text {di.meas. }}\right) * 2\right\}^{1 / 2}\right.
$$

\section{Mean Percentage Error (MPE)}

It is described as the measure of extent of the error of values in terms of percentage of the observed or measured value (Kambezidis et al., 2017):

$$
M P E \%=\frac{1}{n} \sum_{i=1}^{n}\left\{\frac{G_{\text {di.meas. }}-G_{\text {di.calc. }}}{G_{\text {di.meas. }}}\right\} * 100
$$

\section{The t-state}

Model verification can also be done by applying $t$ statistical error. The values close to zero in all models are the models with the best performance. It was proposed by stone (Li et al., 2012b) and the mathematical equation is described in terms of MBE and RMSE as (Bailek et al., 2017; Shamshirband et al., 2016; Behar et al., 2015):

$$
t-\text { state }=\left\{(n-1)(M B E)^{2} /(R M S E)^{2}-(M B E)^{2}\right\}^{1 / 2}
$$

The smaller values of $t$-statistic the better the performance of modeling.

\section{The Correlation Coefficient $\left(R^{2}\right)$}

In statistics literature, it is the proportion of variability in a data set that is accounted for by a statistical model, where the variability is measured quantitatively as the sum of square deviations. Most often it is defined notationally as (Zell et al., 2015):

$$
R=\sum_{i=1}^{n} \frac{\left(G_{\text {di.calc. }}-G_{d \text { calc. }}\right)\left(G_{\text {di.meas. }}-G_{d \text { meas. }}\right)}{\left\{\left(G_{\text {di.calc. }}-G_{d \text { calc. }}\right) * 2\left(G_{\text {di.meas. }}-G_{d \text { meas. }}\right) * 2\right\} * 1 / 2}
$$

where, $G_{\text {di.calc. }}$ and $G_{\text {di.mes. }}$, are the calculate and measure diffuse solar radiation respectively. A high value of $\mathrm{R}^{2}$ is alluring as this appears a lower unexplained variety. $\mathrm{R}^{2}$ may be a measurement that gives a few data almost the goodness-of-fit of a model. In regression, the $\mathrm{R}^{2}$ coefficient of assurance may be a factual measure of how well the regression line approximates the real information points. An $\mathrm{R}^{2}$ of 1.0 clear that the regression line impeccably fits the information, which is never substantial in any solar radiation estimation model.

\section{Uncertainty at $95 \%\left(U_{95}\right)$}

The expanded uncertainty in the $95 \%$ confidence interval is used to represent the data of the model deviation. This can be expressed mathematically using the formula described by Hepbasli and Alsuhaibani (2011):

$U_{95}=1.96\left(S D^{2}+R M S E^{2}\right)^{1 / 2}$

Among them, SD is the percentage standard deviation $\left(\mathrm{W} / \mathrm{m}^{2}\right)$ of the difference between the predicted value and the measured value. In the above formula, 1.96 is the coverage factor corresponding to the $95 \%$ confidence interval.

\section{Global Performance Index (GPI)}

The Global Performance Index (GPI) is called statistical indicator. The values of the statistical indicator have to be compelled to be scale down between zeros to one assist the median value is subtracted from the scaled value of the individual statistical indicator. Finally using the appropriate weight factor for individual statistical indicator GPI is obtained. Mathematical expression for $G P I_{i}$ of the $i$ th model is defined as:

$G P I_{i}=\sum_{j=1}^{10} \alpha j(\tilde{Y} j-Y i j)$

where, $\alpha j$ equals -1 for the correlation coefficient (R) only, while for others indicators is equal to $1, \tilde{Y} j$ is the median of scaled values of indicator $j, Y i j$ is the scaled value of indicator $j$ for model $i$. Higher value of GPI represents better accuracy of the model (Abreu et al., 2019).

\section{Results and Discussion}

The evaluations of the developed models from each case are assessed and compared the results of 19 models presented within the literature. In order to achieve this objective, using measured data covering the period time from 1990 to 2014 for the different four selected locations over Saudi Arabia. From the analysis of the combined data for selected locations in the present study, relationships are obtained to express the diffuse radiation from various parameters. The obtained values of the regression coefficients of the Eq. (20-38), with the Standard Error Estimate (S.E) and the correlation coefficient (R) are listed in Table 2. From this table, we may noticed that, Eq. (23, 28, 30 and 38) have the highest values of correlation 
coefficients, while the lowest values of the correlation coefficients obtained from Eq. (20, 22, 31 and 36). The values of correlation coefficient in other equations lie between highest and lowest values.

Table 3, shows a comparison between all models using the considered statistical indicators. The results of this table reveal that there are some models that can be excluded from the discussion due to either high of t-test (t-test >2) or low of correlation coefficient magnitudes, three models for case 1, two models for case 2 and one model for case 3 at Al-Baha and Jeddah locations, while 2 models for case 1 , three models for case 2 and two models for case 3 at Abha and Taif locations during the period time in the present research. The comes about obtained in this study demonstrate that the sunshine based models are for the most part more precise than models based on the clearness index at the selected locations. Agreeing to the results, the most excellent exhibitions are generally obtained by the quadratic regression models. As given in Table 3, indicating that Eq. (22) achieved the largest GPI and the lowest overall statistical errors at the locations of presented study.

Table 4 shows the comparison of the statistical performance of different case models with the $\left(\mathrm{U}_{95}\right)$ uncertainty index and $(\mathrm{R})$ correlation coefficient during the selected time period during this study. It can be seen from the table that case (1) provides the minimum value of $\mathrm{U}_{95}$ and the maximum value of $\mathrm{R}$. Therefore, compared with case (2), the model based on SD data are shows better performance and (3) for the overall position selected in this study. On the other hand, case (3) provides a higher correlation than case (2). The minimum value $\mathrm{U}_{95}$ of the case (3) is lower than the minimum value $\mathrm{U}_{95}$ of the case (2). Therefore, it is clear that during this period of time, case (3) showed better performance than case (2).

The values of Mean Bias Error (MBE) at the different selected locations during the period time in the present research are show in Fig. 3. The figure indicate that, the MBE underestimation of the diffuse solar radiation is notated numbers of Eq. 8, 10, 8 and 9 for Al-Baha, Abha, Jeddah and Taif respectively and the other numbers of models for the selected locations are overestimation of the diffuse solar radiation. The values of MBE obtained for each of the developed models is fairly small and for most of the models is observed to be quit close to zero. The lowest values of MBE at selected locations in the present study appear for models 22 (closest to zero). Therefore, this is the best model in terms of MBE test indicator. The models presented here are compared with the statistical error. These models have reasonable values estimations errors. Consequently, the model developed in this study can be reliably used to estimate monthly average daily diffuse solar radiation in the different selected locations in the present research and elsewhere with similar climatic conditions.

Figure 4, shows the values of $\mathrm{U}_{95}$ uncertainty indicator at the selected locations during the period time in the present research. The figure clear that, the values of $U_{95}$ for all models at the selected locations in the present study are nearest them. The highest values of $\mathrm{U}_{95}$ are appears in case 2 for models 28, 29, 30 and 31, while the minimum values of $\mathrm{U}_{95}$ occur for model 22 . In addition, the $\mathrm{U}_{95}$ values are similar approximately in cases 1 and 3 with exception models 25 and 36 . Therefore the model 22 is considering the best statistical error in this study.

Table 2: The values of different regression coefficients, standard error and correlation coefficient

\begin{tabular}{|c|c|c|c|c|c|c|c|c|c|}
\hline \multirow[b]{2}{*}{ Models } & \multicolumn{7}{|c|}{ The values of regression coefficients } & \multirow{2}{*}{$\begin{array}{l}\text { Standard } \\
\text { Error (S.E) }\end{array}$} & \multirow{2}{*}{$\begin{array}{l}\text { Correlation } \\
\text { coefficient (R) }\end{array}$} \\
\hline & $\mathrm{a}$ & $\mathrm{b}$ & $\mathrm{c}$ & $\mathrm{d}$ & e & $\mathrm{f}$ & $\mathrm{g}$ & & \\
\hline 20 & 0.642 & -0.391 & - & - & - & - & - & 0.021 & 0.752 \\
\hline 21 & 0.721 & -0.462 & 0.061 & - & - & - & - & 0.041 & 0.862 \\
\hline 22 & 0.215 & 2.123 & -3.547 & 5.142 & - & - & - & 0.035 & 0.789 \\
\hline 23 & 0.213 & -0.462 & - & - & - & - & - & 0.028 & 0.953 \\
\hline 24 & 0.592 & -0.285 & - & - & - & - & - & 0.033 & 0.867 \\
\hline 25 & -0.407 & -0.756 & - & - & - & - & - & 0.027 & 0.912 \\
\hline 26 & -0.208 & 2.191 & -1.905 & - & - & - & - & 0.024 & 0.793 \\
\hline 27 & 0.851 & -0.723 & - & - & - & - & - & 0.045 & 0.886 \\
\hline 28 & 0.465 & 0.291 & -1.121 & - & - & - & - & 0.027 & 0.942 \\
\hline 29 & 0.681 & -0.642 & 0.000 & 0.000 & - & - & - & 0.034 & 0.842 \\
\hline 30 & 0.206 & -0.375 & - & - & - & - & - & 0.038 & 0.934 \\
\hline 31 & 1.121 & -0.252 & - & - & - & - & - & 0.037 & 0.776 \\
\hline 32 & -0.311 & -0.639 & - & - & - & - & - & 0.029 & 0.827 \\
\hline 33 & 0.425 & 0.721 & -0.116 & - & - & - & - & 0.044 & 0.896 \\
\hline 34 & -3.219 & 5.918 & -3.617 & 0.481 & -0.627 & - & - & 0.038 & 0.917 \\
\hline 35 & 9.816 & -16.115 & 35.205 & -41.105 & -5.125 & 5.203 & -2.119 & 0.027 & 0.875 \\
\hline 36 & 0.165 & 0.514 & -0.432 & - & - & - & - & 0.043 & 0.745 \\
\hline 37 & 0.125 & 0.318 & -0.291 & - & - & - & - & 0.026 & 0.835 \\
\hline 38 & -0.891 & -0.211 & -1.327 & - & - & - & - & 0.035 & 0.925 \\
\hline
\end{tabular}


Samy A. Khalil / American Journal of Applied Sciences 2021, Volume 18: 135.151 DOI: 10.3844/ajassp.2021.135.151

Table 3: The statistical test indicators of all models for estimating the DSR on a horizontal surface at selected locations in the present research

\begin{tabular}{|c|c|c|c|c|c|c|c|c|c|c|c|c|c|}
\hline \multicolumn{7}{|c|}{ Al-Baha } & \multicolumn{7}{|l|}{ Abha } \\
\hline Models & MBE & RMSE & MPE & $\mathrm{U}_{95}$ & t-test & GPI & Models & $\mathrm{MBE}$ & RMSE & MPE & $\mathrm{U}_{95}$ & t-test & GPI \\
\hline 20 & 0.065 & 0.859 & -0.024 & 2.215 & 1.112 & 0.312 & 20 & -0.045 & 0.752 & 0.052 & 2.122 & 1.235 & 0.289 \\
\hline 22 & -0.012 & 0.825 & -0.034 & 2.542 & 1.032 & 0.354 & 22 & 0.018 & 0.698 & -0.054 & 2.511 & 1.115 & 0.388 \\
\hline 23 & -0.029 & 0.962 & -0.018 & 2.635 & 2.112 & 0.132 & 23 & -0.051 & 0.924 & 0.027 & 2.532 & 1.515 & 0.145 \\
\hline 24 & 0.085 & 0.873 & -0.022 & 2.812 & 1.524 & 0.125 & 24 & 0.049 & 0.836 & -0.036 & 2.745 & 1.385 & -0.168 \\
\hline 25 & 0.049 & 0.945 & -0.026 & 3.112 & 2.214 & -0.089 & 25 & 0.066 & 0.914 & -0.061 & 3.458 & 2.065 & 0.065 \\
\hline 26 & 0.034 & 1.045 & -0.019 & 2.589 & 1.235 & 0.154 & 26 & 0.052 & 1.134 & -0.045 & 2.457 & 1.323 & 0.124 \\
\hline 27 & -0.041 & 1.032 & 0.013 & 2.547 & 1.324 & 0.231 & 27 & -0.084 & 1.214 & 0.021 & 2.523 & 2.116 & 0.247 \\
\hline 28 & -0.025 & 1.011 & -0.027 & 3.524 & 2.098 & 0.247 & 28 & 0.047 & 1.089 & 0.033 & 3.567 & 1.578 & 0.289 \\
\hline 29 & -0.039 & 0.987 & -0.016 & 3.652 & 1.624 & -0.124 & 29 & -0.025 & 0.875 & -0.062 & 3.524 & 2.032 & 0.158 \\
\hline 30 & -0.066 & 0.892 & -0.015 & 3.952 & 1.457 & -0.213 & 30 & -0.085 & 0.932 & -0.037 & 3.824 & 1.487 & -0.263 \\
\hline 31 & -0.084 & 1.325 & -0.024 & 3.214 & 2.118 & -0.165 & 31 & -0.037 & 1.258 & -0.042 & 3.264 & 2.156 & -0.178 \\
\hline 32 & 0.042 & 1.421 & 0.027 & 2.586 & 1.324 & -0.157 & 32 & -0.069 & 1.354 & 0.051 & 2.475 & 1.411 & -0.124 \\
\hline 33 & 0.037 & 1.245 & 0.014 & 2.214 & 1.265 & 0.123 & 33 & 0.045 & 1.285 & 0.045 & 2.289 & 1.324 & 0.168 \\
\hline 35 & 0.035 & 0.936 & 0.016 & 2.345 & 1.147 & 0.147 & 35 & 0.077 & 0.915 & 0.032 & 2.312 & 2.113 & -0.128 \\
\hline 36 & 0.025 & 1.102 & 0.012 & 3.812 & 2.054 & 0.135 & 36 & -0.048 & 1.137 & 0.028 & 3.724 & 1.415 & 0.167 \\
\hline 37 & 0.031 & 0.893 & 0.015 & 2.145 & 1.246 & 0.245 & 37 & 0.026 & 0.941 & 0.018 & 2.245 & 2.214 & 0.282 \\
\hline 38 & 0.041 & 0.924 & 0.023 & 2.243 & 1.298 & 0.329 & 38 & 0.062 & 0.962 & 0.042 & 2.286 & 1.166 & -0.311 \\
\hline \multicolumn{7}{|l|}{ Jeddah } & \multicolumn{7}{|l|}{ Taif } \\
\hline Models & MBE & RMSE & MPE & $\mathrm{U}_{95}$ & t-test & GPI & Models & $\mathrm{MBE}$ & RMSE & MPE & $\mathrm{U}_{95}$ & t-test & GPI \\
\hline 20 & 0.028 & 0.825 & 0.052 & 2.265 & 1.214 & 0.314 & 20 & -0.057 & 0.724 & 0.047 & 2.185 & 1.261 & 0.262 \\
\hline 21 & -0.029 & 0.935 & -0.027 & 2.19 & 2.084 & 0.289 & 21 & 0.041 & 0.814 & 0.066 & 2.127 & 2.034 & -0.345 \\
\hline 22 & 0.011 & 0.768 & -0.045 & 2.578 & 1.054 & 0.335 & 22 & 0.016 & 0.712 & -0.024 & 2.475 & 1.114 & 0.362 \\
\hline 23 & 0.055 & 0.962 & 0.025 & 2.514 & 1.514 & 0.166 & 23 & 0.037 & 0.854 & -0.045 & 2.475 & 1.345 & -0.125 \\
\hline 24 & -0.064 & 0.892 & -0.037 & 2.754 & 2.125 & -0.147 & 24 & 0.025 & 0.745 & 0.081 & 2.615 & 2.144 & 0.185 \\
\hline 25 & 0.078 & 0.978 & -0.045 & 3.215 & 1.625 & 0.064 & 25 & -0.089 & 0.658 & -0.064 & 3.315 & 1.475 & 0.027 \\
\hline 26 & 0.056 & 1.124 & -.013 & 2.451 & 2.055 & 0.127 & 26 & 0.041 & 1.245 & 0.027 & 2.512 & 1.365 & -0.145 \\
\hline 27 & 0.091 & 1.068 & 0.018 & 2.359 & 1.411 & -0.247 & 27 & -0.047 & 1.145 & 0.063 & 2.471 & 1.192 & 0.289 \\
\hline 28 & 0.042 & 1.032 & -0.042 & 3.568 & 1.485 & 0.189 & 28 & -0.024 & 1.062 & -0.058 & 3.326 & 2.065 & -0.231 \\
\hline 29 & -0.074 & 0.955 & 0.028 & 3.647 & 2.032 & 0.163 & 29 & 0.033 & 0.821 & -0.078 & 3.586 & 2.111 & 0.121 \\
\hline 32 & -0.032 & 1.468 & -0.015 & 2.452 & 1.254 & -0.132 & 32 & -0.044 & 1.247 & -0.024 & 2.274 & 1.475 & 0.189 \\
\hline 33 & 0.056 & 1.289 & 0.024 & 2.324 & 1.145 & -0.162 & 33 & 0.037 & 1.365 & 0.069 & 2.124 & 1.245 & -0.131 \\
\hline 34 & -0.071 & 0.911 & -0.027 & 2.154 & 1.189 & 0.289 & 34 & -0.082 & 0.825 & -0.032 & 2.324 & 1.362 & 0.277 \\
\hline 35 & 0.047 & 0.945 & 0.031 & 2.268 & 1.162 & 0.165 & 35 & -0.051 & 0.962 & 0.041 & 2.411 & 2.175 & 0.165 \\
\hline 36 & 0.034 & 1.124 & -0.025 & 2.715 & 2.219 & -0.144 & 36 & 0.038 & 1.265 & -0.061 & 3.528 & 1.415 & -0.114 \\
\hline 37 & -0.029 & 0.868 & 0.037 & 2.214 & 1.278 & 0.231 & 37 & -0.029 & 0.985 & 0.027 & 2.289 & 1.234 & 0.252 \\
\hline 38 & 0.035 & 0.965 & 0.016 & 2.312 & 1.224 & 0.324 & 38 & 0.042 & 0.945 & 0.031 & 2.225 & 2.035 & -0.305 \\
\hline
\end{tabular}

Table 4: Comparison of the statistical performance of the different cases of models to (U95) uncertainty indicator and (R) correlation coefficient

\begin{tabular}{llllllllll}
\hline Al-Baha & & Case 1 & Case 2 & Case 3 & Abha & & Case 1 & Case 2 & Case 3 \\
\hline U $_{95}$ & Min. & 2.1240 & 2.547 & 2.1450 & U95 & Min. & 2.1220 & 2.4750 & 2.2210 \\
& Max. & 3.1120 & 3.652 & 3.8120 & & Max. & 3.4580 & 3.8240 & 3.7240 \\
R & Min. & 0.8800 & 0.860 & 0.8300 & R & Min. & 0.9100 & 0.8700 & 0.8900 \\
& Max. & 0.9700 & 0.980 & 0.9600 & & Max. & 0.9500 & 0.9400 & 0.9600 \\
Jeddah & & Case 1 & Case 2 & Case 3 & Taif & Case 1 & Case 2 & Case 3 \\
U95 & Min. & 2.1900 & 2.359 & 2.1540 & U95 & Min. & 2.1270 & 2.2740 & 2.1240 \\
& Max. & 3.2150 & 3.758 & 3.7150 & & Max. & 3.3150 & 3.6250 & 3.5280 \\
R & Min. & 0.9200 & 0.900 & 0.8900 & R & Min. & 0.8500 & 0.8400 & 0.8600 \\
& Max. & 0.9800 & 0.970 & 0.8500 & & Max. & 0.9800 & 0.9600 & 0.9400 \\
\hline
\end{tabular}

The test of the leading models to the four chosen areas in Saudi Arabia: Al-Baha, Abha, Jeddah and Taif amid the period time from 2015 to 2018 within the show ponder are appear in Table 5. The leading performing show (22) and the 19 comparative models from the writing were moreover evaluated for the areas of Al-Baha, Abha, Jeddah and Taif in arrange to illustrate the pertinence of the models over a more extensive locale. In Table 5, the come about of different measurable pointers for these models are displayed. 
Samy A. Khalil / American Journal of Applied Sciences 2021, Volume 18: 135.151

DOI: 10.3844/ajassp.2021.135.151

Table 5: The test of the best models to the four selected sites in Saudi Arabia: Al-Baha, Abha, Jedda and Taif

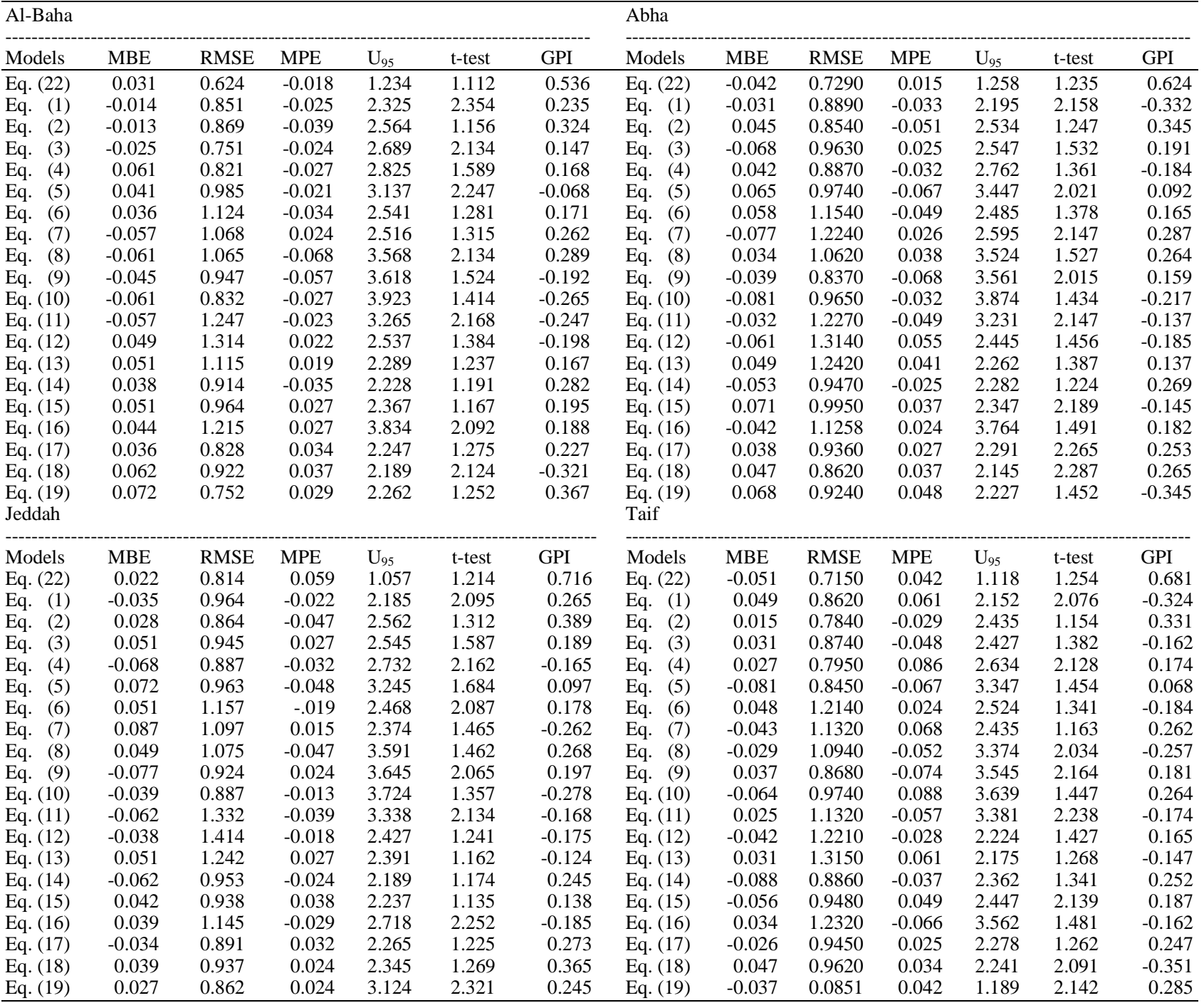

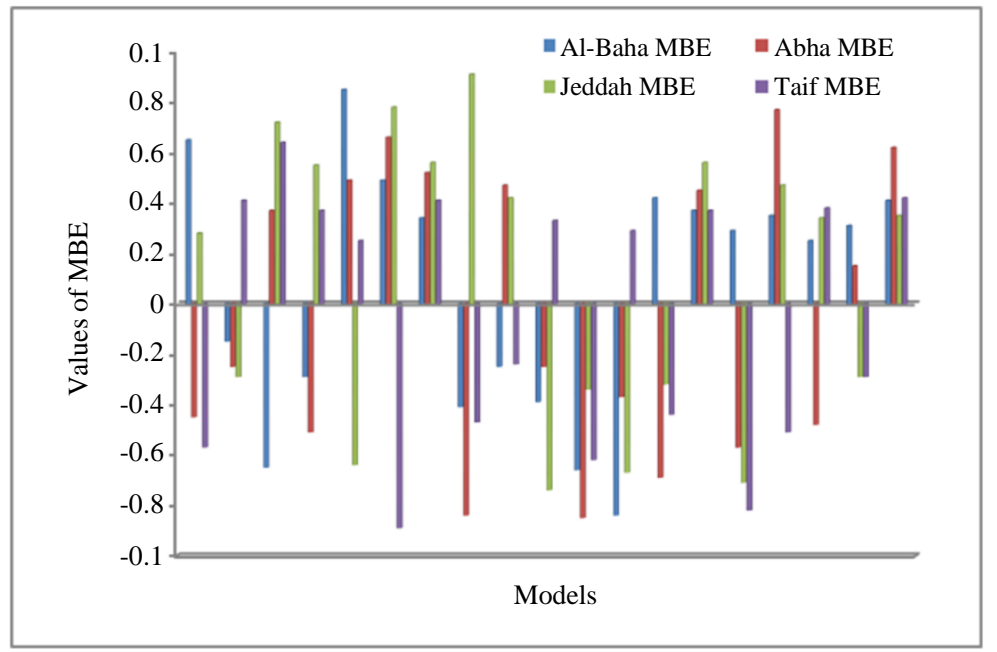

Fig. 3: The values of MBE at the selected locations during the period time in the present research 


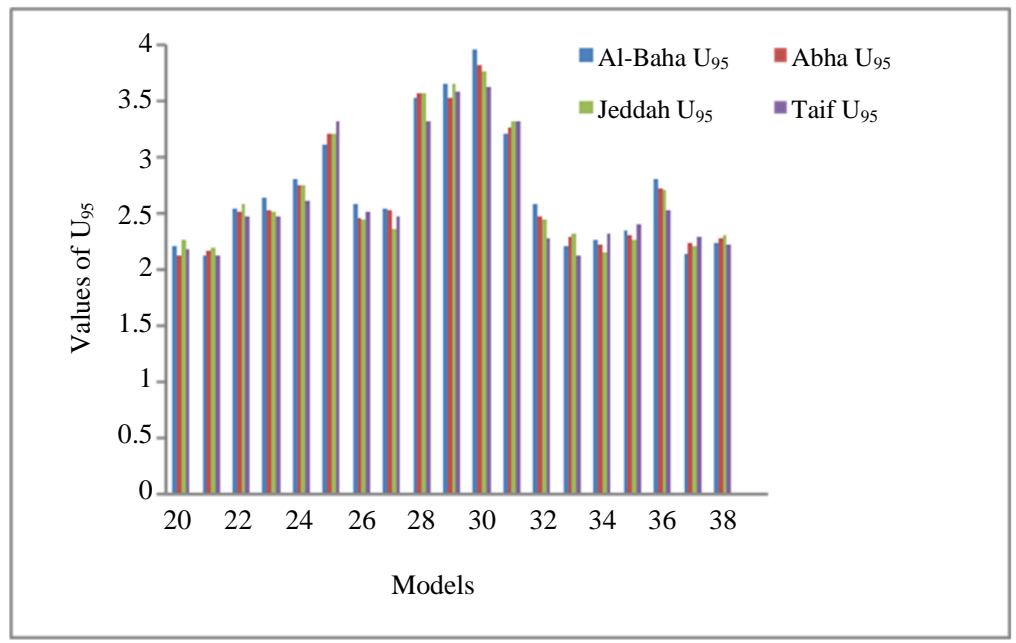

Fig. 4: The values of $U_{95}$ uncertainty indicator at the selected locations during the period time in the present research
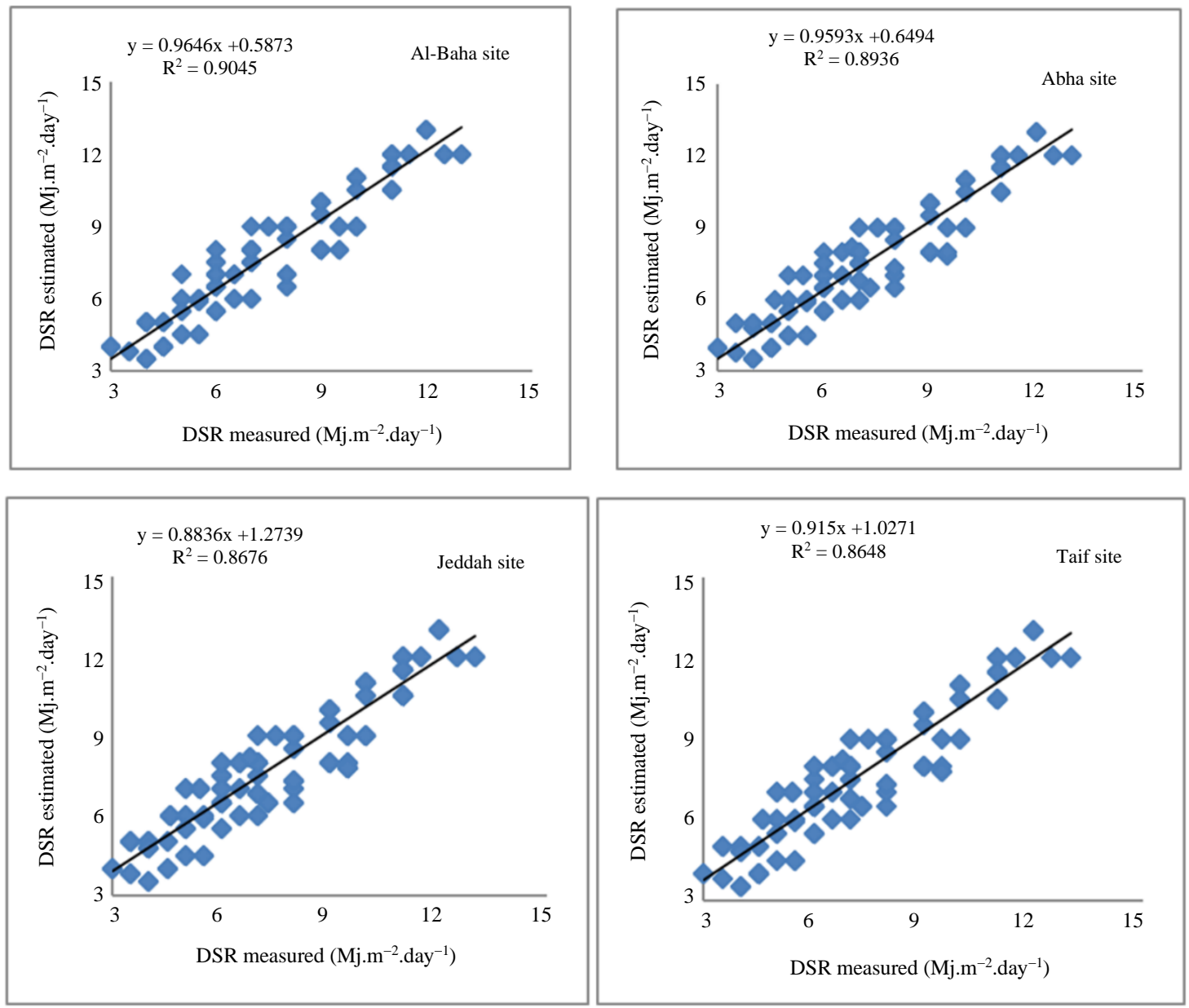

Fig. 5: The correlation coefficients between DSR measured and estimated values at the selected locations during the period time from 2015 to 2018 in the present research

It is clearly seen that the 22 show has the finest real values among all designated models for the four areas, it to boot justified by the foremost hoisted esteem of GPI. In extension, the RMSE values of Al-Baha, Abha, Jeddah and Taif are 0.624, 0.729, 0.814 and 0.715 independently. All sites have higher values of Global Performance Indicator 
(GPI). It is obvious from the results that the past models of the Saudi Arabia appear low accuracy levels within the four considered locales. This ascribed to the fragmented data used in developing these models. Figure 5, shows the correlation coefficients between DSR measured and estimated values at the selected locations during the period time from 2015 to 2018 in the present research. From this figure, we cleared that, there is a strong correlation coefficient of the new model when compared with the measured data of the DSR. $\mathrm{R}$ is equal 95, 94, 93 and 93\% of DSR for Al-Baha, Abha, Jeddah and Taif respectively.

\section{Conclusion}

Confirmation of diffuse solar radiation is basic for sun oriented frameworks plan and change. In this setting, nineteen proposed connections for diffuse sun powered radiation component are overviewed and their execution compared to measured illumination of four chosen areas utilizing different measurable parameters such as MBE, MPE, RMSE, t-statistic and GPI. The created relationships are connected to compute the month-to-month normal day by day diffuse illumination of Al-Baha, Abha, Jeddah and Taif locations. The diffuse component of worldwide radiation is connected with the daylight hour division, the relative clearness record and with a combination of them. Advance, the execution of these models was too assessed against a set of nineteen models displayed inside the writing. The proposed demonstrate uncovered precise comes about in comparison to these existing models with the most reduced measurable blunders. Agreeing to these comes about the demonstrate 22 gives most noteworthy esteem of GPI. In this way, it is concluded that the cubic condition demonstrates of diffuse division (i.e., $D / G=0.215+2.123\left(\mathrm{~S} / \mathrm{S}_{\mathrm{o}}\right)$ $3.547\left(\mathrm{~S} / \mathrm{S}_{\mathrm{o}}\right)^{2}+5.142\left(\mathrm{~S} / \mathrm{S}_{\mathrm{o}}\right)^{3}$ is chosen as the foremost exact show which has been specified within the previous talk. This show is generalized condition for the Saudi Arabia locale and is able to appraise the month to month normal every day diffuse illumination on a level surface for any destinations in comparative conditions of climate, within the nonappearance of the measured one.

In extension, this appear can be utilized by investigators or engineers in terms of area assurance and technoeconomic execution appraisal of sun-oriented vitality applications particularly those depending on photovoltaic technologies.

\section{Ethics}

This article is original and contains unpublished material. The corresponding author confirms that all of the other authors have read and approved the manuscript and no ethical issues involved.

\section{References}

Abal, G., Aicardi, D., Suárez, R. A., \& Laguarda, A. J. S. E. (2017). Performance of empirical models for diffuse fraction in Uruguay. Solar Energy, 141, 166-181. doi.org/10.1016/j.solener.2016.11.030

Abreu, E. F., Canhoto, P., \& Costa, M. J. (2019). Prediction of diffuse horizontal irradiance using a new climate zone model. Renewable and Sustainable Energy Reviews, 110, 28-42. doi.org/10.1016/j.rser.2019.04.055

Al-Hamdani, N., Al-Riahi, M., \& Tahir, K. (1989). Estimation of the diffuse fraction of daily and monthly average global radiation for Fudhaliyah, Baghdad (Iraq). Solar Energy, 42(1), 81-85. doi.org/10.1016/0038-092X(89)90132-1

Al-Mohamad, A. (2004). Global, direct and diffuse solarradiation in Syria. Applied Energy, 79(2), 191-200. doi.org/10.1016/j.apenergy.2003.12.011

Aras, H., Balli, O., \& Hepbasli, A. (2006). Estimating the horizontal diffuse solar radiation over the Central Anatolia Region of Turkey. Energy Conversion and Management, 47(15-16), 2240-2249. doi.org/10.1016/j.enconman.2005.11.024

Bailek, N., Bouchouicha, K., Al-Mostafa, Z., El-Shimy, M., Aoun, N., Slimani, A., \& Al-Shehri, S. (2018). A new empirical model for forecasting the diffuse solar radiation over Sahara in the Algerian Big South. Renewable Energy, 117, 530-537. doi.org/10.1016/j.renene.2017.10.081

Bailek, N., Bouchouicha, K., El-Shimy, M., \& Slimani, A. (2017). Updated status of renewable and sustainable energy projects in Algeria. Economics of Variable Renewable Sources for Electric Power Production. Lambert Academic Publishing, Germany.

Bakirci, K. (2012). The calculation of diffuse radiation on a horizontal surface for solar energy applications. Energy Sources, Part A: Recovery, Utilization and Environmental Effects, 34(10), 887-898. doi.org/10.1080/15567031003699525

Bakirci, K. (2015). Models for the estimation of diffuse solar radiation for typical cities in Turkey. Energy, 82, 827-838. doi.org/10.1016/j.en-ergy.2015.01.093

Bashahu, M. (2003). Statistical comparison of models for estimating the monthly average daily diffuse radiation at a subtropical African site. Solar Energy, 75(1), 43-51. doi.org/10.1016/S0038-092X(03)00213-5

Behar, O., Khellaf, A., \& Mohammedi, K. (2015). Comparison of solar radiation models and their validation under Algerian climate-The case of direct irradiance. Energy Conversion and Management, 98, 236-251. doi.org/10.1016/j.enconman.2015.03.067 
Boland, J., Huang, J., \& Ridley, B. (2013). Decomposing global solar radiation into its direct and diffuse components. Renewable and Sustainable Energy Reviews, 28, 749-756. doi.org/10.1016/j.rser.2013.08.023

Boland, J., Ridley, B., \& Brown, B. (2008). Models of diffuse solar radiation. Renewable Energy, 33(4), 575-584. doi.org/10.1016/j.renene.2007.04.012

Boland, J., Scott, L., \& Luther, M. (2001). Modelling the diffuse fraction of global solar radiation on a horizontal surface. Environmetrics: The Official Journal of the International Environmetrics Society, 12(2), 103-116. doi.org/10.1002/1099095X(200103)12:2<103::AID-ENV447>3.0.CO;2-2

Bortolini, M., Gamberi, M., Graziani, A., Manzini, R., \& Mora, C. (2013). Multi-location model for the estimation of the horizontal daily diffuse fraction of solar radiation in Europe. Energy Conversion and Management, 67, 208-216.

doi.org/10.1016/j.encon-man.2012.11.008

Boukelia, T. E., Mecibah, M. S., \& Meriche, I. E. (2014). General models for estimation of the monthly mean daily diffuse solar radiation (Case study: Algeria). Energy Conversion and Management, 81, 211-219. doi.org/10.1016/j.enconman.2014.02.035

Bouzid, Z., \& Ghellai, N. (2015, December). Estimation of solar radiation on inclined surface and design method for an autonomous photovoltaic system. Application to Algeria. In $20153^{\text {rd }}$ International Renewable and Sustainable Energy Conference (IRSEC) (pp. 1-6). IEEE.

doi.org/10.1109/IRSEC.2015.7454931

Božnar, M. Z., Grašič, B., de Oliveira, A. P., Soares, J., \& Mlakar, P. (2017). Spatially transferable regional model for half-hourly values of diffuse solar radiation for general sky conditions based on perceptron artificial neural networks. Renewable Energy, 103, 794-810. doi.org/10.1016/j.renene.2016.11.013

Cao, F., Li, H., Yang, T., Li, Y., Zhu, T., \& Zhao, L. (2017). Evaluation of diffuse solar radiation models in Northern China: New model establishment and radiation sources comparison. Renewable Energy, 103, 708-720. doi.org/10.1016/j.re-nene.2016.11.004

De Miguel, A. B. J. A. R. K. H., Bilbao, J., Aguiar, R., Kambezidis, H., \& Negro, E. (2001). Diffuse solar irradiation model evaluation in the north Mediterranean belt area. Solar energy, 70(2), 143-153. doi.org/10.1016/S0038-092X(00)00135-3

Dervishi, S., \& Mahdavi, A. (2012). Computing diffuse fraction of global horizontal solar radiation: A model comparison. Solar Energy, 86(6), 1796-1802. doi.org/ 10.1016/j.solener.2012.03.008
Despotovic, M., Nedic, V., Despotovic, D., \& Cvetanovic, S. (2016). Evaluation of empirical models for predicting monthly mean horizontal diffuse solar radiation. Renewable and Sustainable Energy Reviews, 56, 246-260. doi.org/10.1016/j.rser.2015.11.058

Diez-Mediavilla, M., De Miguel, A., \& Bilbao, J. (2005). Measurement and comparison of diffuse solar irradiance models on inclined surfaces in Valladolid (Spain). Energy Conversion and Management, 46(13-14), 2075-2092. doi.org/10.1016/j.enconman.2004.10.023

Duffie, J. A., \& Beckman, W. A. (2006). Solar engineering of thermal processes, $3^{\text {rd }}$, Hoboken.

Ekren, O. (2013). Developing and evaluation of various correlations for diffuse solar radiation for Urla (Izmir, Turkey). Journal of solar energy engineering, 135(2). doi.org/10.1115/1.4007855

El Mghouchi, Y., El Bouardi, A., Choulli, Z., \& Ajzoul, T. (2016). Models for obtaining the daily direct, diffuse and global solar radiations. Renewable and Sustainable Energy Reviews, 56, 87-99. doi.org/10.1016/j.rser.2015.11.044

Elminir, H. K., Azzam, Y. A., \& Younes, F. I. (2007). Prediction of hourly and daily diffuse fraction using neural network, as compared to linear regression models. Energy, 32(8), 1513-1523. doi.org/10.1016/j.energy.2006.10.010

El-Sebaii, A. A., \& Trabea, A. A. (2003). Estimation of horizontal diffuse solar radiation in Egypt. Energy Conversion and Management, 44(15), 2471-2482. doi.org/10.1016/S0196-8904(03)00004-9

El-Sebaii, A. A., Al-Hazmi, F. S., Al-Ghamdi, A. A., \& Yaghmour, S. J. (2010). Global, direct and diffuse solar radiation on horizontal and tilted surfaces in Jeddah, Saudi Arabia. Applied Energy, 87(2), 568-576. doi.org/10.1016/j.apenergy.2009.06.032

Furlan, C., De Oliveira, A. P., Soares, J., Codato, G., \& Escobedo, J. F. (2012). The role of clouds in improving the regression model for hourly values of diffuse solar radiation. Applied Energy, 92, 240-254. doi.org/10.1016/j.ape-nergy.2011.10.032

Gopinathan, K. K. (1988). Empirical correlations for diffuse solar irradiation. Sol. Energy; (United Kingdom), 40(4). doi.org/10.1016/0038-092X(88)90009-6

Hepbasli, A., \& Alsuhaibani, Z. (2011). A key review on present status and future directions of solar energy studies and applications in Saudi Arabia. Renewable and Sustainable Energy Reviews, 15(9), 5021-5050. doi.org/10.1016/j.rser.2011.07.052

Ibrahim, S. M. (1985). Diffuse solar radiation in Cairo, Egypt. Energy Conversion and Management, 25(1), 69-72. doi.org/10.1016/0196-8904(85)90072-X 
Iqbal, M. (1979). A study of Canadian diffuse and total solar radiation data-II Monthly average hourly horizontal radiation. Solar Energy, 22(1).87-90. doi.org/10.1016/0038-092X(79)90064-1

Jacovides, C. P., Tymvios, F. S., Assimakopoulos, V. D., \& Kaltsounides, N. A. (2006). Comparative study of various correlations in estimating hourly diffuse fraction of global solar radiation. Renewable Energy, 31(15), 2492-2504.

dx.doi.org/10.1016/j.re- nene.2005.11.009

Jafari, S., \& Javaran, E. J. (2012). An optimum slope angle for solar collector systems in Kerman using a new model for diffuse solar radiation. Energy Sources, Part A: Recovery, Utilization and Environmental Effects, 34(9), 799-809. dx.doi.org/10.1080/15567031003645569

Jamil, B., \& Akhtar, N. (2015). Statistical analysis of short-term solar radiation data over Aligarh (India). In Progress in Clean Energy, Volume 2 (pp. 937-948). Springer, Cham. doi.org/10.1007/978-3-319-17031-2_61

Jamil, B., Siddiqui, A. T., \& Akhtar, N. (2016). Estimation of solar radiation and optimum tilt angles for south-facing surfaces in Humid Subtropical Climatic Region of India. Engineering Science and Technology, an International Journal, 19(4), 1826-1835. doi.org/10.1016/j.jestch.2016.10.004

Jiang, Y. (2009a). Correlation for diffuse radiation from global solar radiation and sunshine data at Beijing, China. Journal of Energy Engineering, 135(4), 107-111. doi.org/10.1061/(ASCE)07339402(2009)135:4(107)

Jiang, Y. (2009b). Estimation of monthly mean daily diffuse radiation in China. Applied Energy, 86(9), 1458-1464. doi.org/10.1016/j.apenergy.2009.01.002

Jin, Z., Yezheng, W., \& Gang, Y. (2004). Estimation of daily diffuse solar radiation in China. Renewable Energy, 29(9), 1537-1548. doi.org/10.1016/j.re-nene.2004.01.014

Kambezidis, H. D., Psiloglou, B. E., Karagiannis, D., Dumka, U. C., \& Kaskaoutis, D. G. (2017). Meteorological Radiation Model (MRM v6. 1): Improvements in diffuse radiation estimates and a new approach for implementation of cloud products. Renewable and Sustainable Energy Reviews, 74, 616-637. doi.org/10.1016/j.rser.2017.02.058

Karatasou, S., Santamouris, M., \& Geros, V. (2003). Analysis of experimental data on diffuse solar radiation in Athens, Greece, for building applications. International Journal of Sustainable Energy, 23(1-2), 1-11. doi.org/10.1080/0142591031000148597
Kaygusuz, K. (1999). The comparison of measured and calculated solar radiations in Trabzon, Turkey. Energy Sources, 21(4), 347-353. doi.org/10.1080/00908319950014830

Khahro, S. F., Tabbassum, K., Talpur, S., Alvi, M. B., Liao, X., \& Dong, L. (2015). Evaluation of solar energy resources by establishing empirical models for diffuse solar radiation on tilted surface and analysis for optimum tilt angle for a prospective location in southern region of Sindh, Pakistan. International Journal of Electrical Power \& Energy Systems, 64, 1073-1080. doi.org/10.1016/j.ijepes.2014.09.001

Khalil, S. A. (2007). Empirical correlations for diffuse solar radiation from global solar radiation and sunshine duration over Egypt. Al-Azhar Bulletin of Science, 14(2), 203-210.

Khalil, S. A., \& Shaffie, A. M. (2013). A comparative study of total, direct and diffuse solar irradiance by using different models on horizontal and inclined surfaces for Cairo, Egypt. Renewable and Sustainable Energy Reviews, 27, 853-863. doi.org/10.1016/j.rser.2013.06.038

Khalil, S. A., Shaffie, A. M., El Gohary, H. G., Elshafia, F. M. B., \& Ahmoud, A. A. (2019). Statistical Evaluation of Potential Solar Energy for Al-Baha location, Saudi Arabia. Albaha University Journal of Basic and Applied Sciences, 3(1), 7-20.

Khatib, T., Mohamed, A., Mahmoud, M., \& Sopian, K. (2011). Modeling of daily solar energy on a horizontal surface for five main sites in Malaysia. International Journal of Green Energy, 8(8), 795-819. doi.org/10.1080/15435075.2011.602156

Khorasanizadeh, H., \& Mohammadi, K. (2016). Diffuse solar radiation on a horizontal surface: Reviewing and categorizing the empirical models. Renewable and Sustainable Energy Reviews, 53, 338-362. doi.org/10.1016/j.rser.2015.08.037

Khorasanizadeh, H., Mohammadi, K., \& Goudarzi, N. (2016). Prediction of horizontal diffuse solar radiation using clearness index based empirical models; A case study. International Journal of Hydrogen Energy, 41(47), 21888-21898. doi.org/10.1016/j.ijhy-dene.2016.09.198

Khorasanizadeh, H., Mohammadi, K., \& Mostafaeipour, A. (2014). Establishing a diffuse solar radiation model for determining the optimum tilt angle of solar surfaces in Tabass, Iran. Energy Conversion and Management, 78, 805-814. doi.org/10.1016/j.enconman.2013.

Klein, S. A. (1977). Calculation of monthly average insolation on tilted surfaces. Solar energy, 19(4), 325-329. doi.org/10.1016/0038-092X(77)90001-9 
Lemos, L. F., Starke, A. R., Boland, J., Cardemil, J. M., Machado, R. D., \& Colle, S. (2017). Assessment of solar radiation components in Brazil using the BRL model. Renewable Energy, 108, 569-580. doi.org/10.1016/j.renene.2017.02.077

Lewis, G. (1983). Diffuse irradiation over Zimbabwe. Sol. Energy;(United Kingdom), 31(1), 125-8. https://www.osti.gov/etdeweb/biblio/6928148

Li, D. H., Lou, S. W., \& Lam, J. C. (2015). An analysis of global, direct and diffuse solar radiation. Energy Procedia, 75, 388-393. doi.org/10.1016/j.egy-pro.2015.07.399

Li, H., Bu, X., Long, Z., Zhao, L., \& Ma, W. (2012a). Calculating the diffuse solar radiation in regions without solar radiation measurements. Energy, 44(1), 611-615. doi.org/10.1016/j.energy.2012.05.033

Li, H., Bu, X., Lian, Y., Zhao, L., \& Ma, W. (2012b). Further investigation of empirically derived models with multiple predictors in estimating monthly average daily diffuse solar radiation over China. Renewable Energy, 44, 469-473. doi.org/10.1016/j.renene.2012.01.104

Li, H., Ma, W., Wang, X., \& Lian, Y. (2011). Estimating monthly average daily diffuse solar radiation with multiple predictors: A case study. Renewable Energy, 36(7), 1944-1948. doi.org/10.1016/j.renene.2011.01.006

Liu, B. Y., \& Jordan, R. C. (1960). The interrelationship and characteristic distribution of direct, diffuse and total solar radiation. Solar Energy, 4(3), 1-19. doi.org/10.1016/0038-092X(60)90062-1

Lou, S., Li, D. H., Lam, J. C., \& Chan, W. W. (2016). Prediction of diffuse solar irradiance using machine learning and multivariable regression. Applied Energy, 181, 367-374. doi.org/10.1016/j.apenergy.2016.08.093

Magarreiro, C., Brito, M. C., \& Soares, P. M. M. (2014). Assessment of diffuse radiation models for cloudy atmospheric conditions in the Azores region. Solar Energy, 108, 538-547. doi.org/10.1016/j.solener.2014.08.003.

Marques Filho, E. P., Oliveira, A. P., Vita, W. A., Mesquita, F. L., Codato, G., Escobedo, J. F., ... \& França, J. R. A. (2016). Global, diffuse and direct solar radiation at the surface in the city of Rio de Janeiro: Observational characterization and empirical modeling. Renewable Energy, 91, 64-74. doi.org/10.1016/j.renene.2016.01.040

Mohammadi, K., Shamshirband, S., Petković, D., \& Khorasanizadeh, H. (2016). Determining the most important variables for diffuse solar radiation prediction using adaptive neuro-fuzzy methodology; case study: City of Kerman, Iran. Renewable and Sustainable Energy Reviews, 53, 1570-1579. doi.org/10.1016/j.rser.2015.09.028
Mubiru, J., \& Banda, E. J. K. B. (2007). Performance of empirical correlations for predicting monthly mean daily diffuse solar radiation values at Kampala, Uganda. Theoretical and Applied Climatology, 88(1), 127-131. doi.org/10.1007/s00704-006-0249-1

Noorian, A. M., Moradi, I., \& Kamali, G. A. (2008). Evaluation of 12 models to estimate hourly diffuse irradiation on inclined surfaces. Renewable Energy, 33(6), 1406-1412. doi.org/10.1016/j.renene.2007.06.027

Oliveira, A. P., Escobedo, J. F., Machado, A. J., \& Soares, J. (2002). Correlation models of diffuse solar-radiation applied to the city of Sao Paulo, Brazil. Applied Energy, 71(1), 59-73. doi.org/10.1016/S0306-2619(01)00040-X

Page, J. (1961). The estimation of monthly mean values of daily total short wave radiation on vertical and inclined surfaces from sunshine records for latitudes 40N-40S. In: UN Conference on New Sources of Energy (1961: Rome) (DHLAUTH)452510, (pp. 8), New York: UN. https://digitallibrary.un.org/record/3827996?ln=en

Paulescu, E., \& Blaga, R. (2016). Regression models for hourly diffuse solar radiation. Solar Energy, 125, 111-124. doi.org/10.1016/j.solener.2015.11.044

Ruiz-Arias, J. A., Alsamamra, H., Tovar-Pescador, J., \& Pozo-Vázquez, D. (2010). Proposal of a regressive model for the hourly diffuse solar radiation under all sky conditions. Energy Conversion and Management, 51(5), 881-893. doi.org/10.1016/j.encon-man.2009.11.024

Sabzpooshani, M., \& Mohammadi, K. (2014). Establishing new empirical models for predicting monthly mean horizontal diffuse solar radiation in city of Isfahan, Iran. Energy, 69, 571-577. doi.org/10.1016/j.energy.2014.03.051

Safaripour, M. H., \& Mehrabian, M. A. (2011). Predicting the direct, diffuse and global solar radiation on a horizontal surface and comparing with real data. Heat and Mass Transfer, 47(12), 1537-1551. doi.org/10.1007/s00231-011-0814-8

Şenkal, O., \& Kuleli, T. (2009). Estimation of solar radiation over Turkey using artificial neural network and satellite data. Applied Energy, 86(7-8), 1222-1228. doi.org/10.1016/j.apenergy.2008.06.003

Shamshirband, S., Mohammadi, K., Khorasanizadeh, H., Yee, L., Lee, M., Petković, D., \& Zalnezhad, E. (2016). Estimating the diffuse solar radiation using a coupled support vector machine-wavelet transform model. Renewable and Sustainable Energy Reviews, 56, 428-435. doi.org/10.1016/j.rser.2015.11.055 
Shukla, K. N., Rangnekar, S., \& Sudhakar, K. (2016a). Mathematical modelling of solar radiation incident on tilted surface for photovoltaic application at Bhopal, MP, India. International Journal of Ambient Energy, 37(6), 579-588. doi.org/10.1080/01430750.2015.1023834

Shukla, A. K., Sudhakar, K., \& Baredar, P. (2016b). Exergetic analysis of building integrated semitransparent photovoltaic module in clear sky condition at Bhopal India. Case Studies in Thermal Engineering, 8, 142-151. doi.org/10.1016/j.csite.2016.06.009

Shukla, A. K., Sudhakar, K., \& Baredar, P. (2016c). Exergetic assessment of BIPV module using parametric and photonic energy methods: A review. Energy and Buildings, 119, 62-73. doi.org/10.1016/j.enbuild.2016.03.022

Shukla, A. K., Sudhakar, K., \& Baredar, P. (2016d). Design, simulation and economic analysis of standalone roof top solar PV system in India. Solar Energy, 136, 437-449. doi.org/10.1016/j.solener.2016.07.009

Shukla, A. K., Sudhakar, K., \& Baredar, P. (2016e). Simulation and performance analysis of $110 \mathrm{kWp}$ grid-connected photovoltaic system for residential building in India: A comparative analysis of various PV technology. Energy Reports, 2, 82-88. doi.org/10.1016/j.egyr.2016.04.001

Shukla, A. K., Sudhakar, K., \& Baredar, P. (2016f). A comprehensive review on design of building integrated photovoltaic system. Energy and Buildings, 128, 99-110. doi.org/10.1016/j.enbuild.2016.06.077

Shukla, K. N., Rangnekar, S., \& Sudhakar, K. (2015a). Comparative study of isotropic and anisotropic sky models to estimate solar radiation incident on tilted surface: A case study for Bhopal, India. Energy Reports, 1, 96-103. doi.org/10.1016/j.egyr.2015.03.003

Shukla, K. N., Sudhakar, K., \& Rangnekar, S. (2015b). Estimation and validation of solar radiation incident on horizontal and tilted surface at Bhopal, Madhya Pradesh, India. American-Eurasian Journal of Agricultural \& Environmental Sciences, 15, 129-139. https://www.cabdirect.org/cabdirect/abstract/201531 42612
Shukla, K. N., Rangnekar, S., \& Sudhakar, K. (2015c). A comparative study of exergetic performance of amorphous and polycrystalline solar PV modules. International Journal of Exergy, 17(4), 433-455. doi.org/10.1504/IJEX.2015.071559.

Soares, J., Oliveira, A. P., Božnar, M. Z., Mlakar, P., Escobedo, J. F., \& Machado, A. J. (2004). Modeling hourly diffuse solar-radiation in the city of São Paulo using a neural-network technique. Applied Energy, 79(2), 201-214. doi.org/10.1016/j.ape-nergy.2003.11.004

Tapakis, R., Michaelides, S., \& Charalambides, A. G. (2016). Computations of diffuse fraction of global irradiance: Part 1-Analytical modelling. Solar Energy, 139, 711-722. doi.org/10.1016/j.solener.2014.10.005

Tarhan, S., \& Sar1, A. (2005). Model selection for global and diffuse radiation over the Central Black Sea (CBS) region of Turkey. Energy Conversion and Management, 46(4), 605-613. doi.org/10.1016/j.enconman.2004.04.004

Trabea, A. A. (1999). Technical note a multiple linear correlation for diffuse radiation from global solar radiation and sunshine data over Egypt. Renewable Energy, 17(3), 411-420. doi.org/10.1016/S0960-1481(98)00124-4

Ulgen, K., \&Hepbasli. (2003). Comparison of the diffuse fraction of daily and monthly global radiation for Izmir, Turkey. Energy Sources, 25(7), 637-649. doi.org/10.1080/00908310390212444

Ulgen, K., \& Hepbasli, A. (2009). Diffuse solar radiation estimation models for Turkey's big cities. Energy Conversion and management, 50(1), 149-156. doi.org/10.1016/j.enconman.2008.08.013

Wattan, R., \& Janjai, S. (2016). An investigation of the performance of 14 models for estimating hourly diffuse irradiation on inclined surfaces at tropical sites. Renewable Energy, 93, 667-674. doi.org/10.1016/j.renene.2016.02.076.

Yao, W., Zhang, C., Wang, X., Sheng, J., Zhu, Y., \& Zhang, S. (2017). The research of new daily diffuse solar radiation models modified by Air Quality Index (AQI) in the region with heavy fog and haze. Energy Conversion and Management, 139, 140-150. doi.org/10.1016/j.enconman.2017.02.041

Zell, E., Gasim, S., Wilcox, S., Katamoura, S., Stoffel, T., Shibli, H. \& Al Subie M. (2015). Assessment of solar radiation resources in Saudi Arabia. Solar Energy, 119, 422-438. doi.org/10.1016/j.solener.2015.06.031 